\title{
Structural and optical characteristic of 1-(4-Methylsulfonyl Phenyl)-3-(4-n, n Dimethyl (amino Phenyl)-2-Propen- 1-One (MSPPP) Chalcone doped ZnO nanoparticles
}

\author{
Mohana F. Attia ${ }^{a,{ }^{*}}$, Abdelrahman A. Elbadawi ${ }^{b}$
}

a Department of Mechanical Engineering - Physics, Alasala Engineering College, Saudi Arabia.

a Faculty of Science and Technology, School of Physics, Alneelain University, Sudan.

*Corresponding author Email: mohana.attia@alasala.edu.sa

DOI: https://doi.org/10.34256/nnxt2114

Received: 20-03-2021; Accepted: 29-03-2021; Published: 30-03-2021

Abstract: The purpose of this paper is to investigate the structural and optical characteristics of 1-(4Methylsulfonyl Phenyl)-3-(4-n, n Dimethyl (amino Phenyl)-2-Propen- 1-One (MSPPP) Chalcone doped in ZnO nanoparticles. Part of the aim is to study the characterization of chalcone doped $\mathrm{ZnO}$ nanoparticles by several techniques such as X-ray diffraction, Scanning electron microscope, FTIR spectroscopy, and diffuse reflection spectra. All doped samples showed a hexagonal wurtzite structure. This study has shown that the crystallite size of pure $\mathrm{ZnO}$ varied from 23.50 to $27.45 \mathrm{~nm}$ and when increasing the chalcone percentage by 0.5 and $1.5 \%$, has increased the crystallite sizes in the range of $33.40-33.80 \mathrm{~nm}$ and $33.80-36.20 \mathrm{~nm}$, respectively. The value of the energy gap (Eg) for $\mathrm{ZnO}$ nanoparticles was $3.14 \mathrm{eV}$. For 0.5 and $1.5 \%$ chalcone doped $\mathrm{ZnO}$, the energy gap decreased by an order of magnitude $0.16 \mathrm{eV}$.

Keywords: ZnO, Spectroscopic studies, optical, Structural

\section{Introduction}

Zinc oxide $(\mathrm{ZnO})$ nanoparticles plays a vital role and are extensively utilized in different applications because of their properties $[1,2]$. ZnO nanoparticle own a broad bandgap of $3.37 \mathrm{eV}$, a large exciton binding energy of $60 \mathrm{~m} \mathrm{eV}$ and is an n-type semiconductor material $[3,6]$. Owing all these properties, it has found widely utilize in different technological application, like laser, photocatalyst, gas sensors and solar cell $[7,8]$. Additionally, compared to other metal oxides it is economical, easy to fabricate and environmentally [9]. By doping with various materials, the properties of $\mathrm{ZnO}$ can be tuned to acquire particular properties [10]. Doping can lead fundamental changes in $\mathrm{ZnO}$ 's physical behavior [6]. Most studies noted that variations happen by incorporation of transition metal ions into $\mathrm{ZnO}$ lattice $[11,12]$. Chalcone derivatives have a functionality of a carbonyl group in conjugation with a carbon-carbon double bond, which is known as a, $\beta$-unsaturated keto group. The desirable properties of the chalcones are: adding/removing donor can modify high conjugation level; and the photophysical characteristics of these chalcones or acceptor groups the skeleton [13, 14]. The doping of $\mathrm{ZnO}$ with other materials (heterostructures) has attracted significant interests from their predominant properties to combine two kinds of materials with lower photoexcitation threshold than individual components and decrease the recombination rate of electron-hole pairs by their physically separated band gap $[15,16]$. The essential purpose of the present work is to report on the photophysical properties of $\mathrm{ZnO}$ nanoparticles doped with the chalcone (MSPPP) in order to obtain novel proprieties through alloying and doping materials. This investigation is an attempt to highlight the behavior of chalcones doped $\mathrm{ZnO}$ nanoparticles as a novel material for optoelectronics applications.

\section{Experimental Section}

\subsection{Chalcone synthesis}

Chalcone material of 1-(4-methylsulfonyl phenyl)-3-(4-N, N dimethyl (amino phenyl)-2-propen-1one (MSPPP) was performed using a simple reaction of 4- dimethylamino benzaldahyde $(0.01 \mathrm{~mol})$ and acetophenones derivatives $(0.01 \mathrm{~mol})$ in a basic solution of sodium hydroxide $(1.0 \mathrm{gm})$ and ethanol (50 $\mathrm{ml}$ ). The product was recrystallized from ethanol and water, filtered, washed with water, and left to dry [17]. 
The molecular structure of the chalcone is given in Fig. 1. The product confirmed by $\mathrm{H} 1 \mathrm{NMR}$ and UV -Vis spectroscopy. $400 \mathrm{MHz}$, from 0 to $11 \mathrm{ppm}){ }^{1} \mathrm{NMR}$ : $\delta$ $2.86(6 \mathrm{H}, \mathrm{s}), 3.07(3 \mathrm{H}, \mathrm{s}), 6.47(1 \mathrm{H}, \mathrm{d}, \mathrm{J}=15.6 \mathrm{~Hz})$, $6.84(2 \mathrm{H}$, ddd, $\mathrm{J}=8.2,1.2,0.4 \mathrm{~Hz}), 7.47-7.58(3 \mathrm{H}$, $7.51(\mathrm{~d}, \mathrm{~J}=15.6 \mathrm{~Hz}), 7.55(\mathrm{ddd}, \mathrm{J}=8.2,1.5,0.5 \mathrm{~Hz})$ ), $7.81(2 \mathrm{H}, \mathrm{ddd}, \mathrm{J}=7.9,1.9,0.5 \mathrm{~Hz}), 8.01(2 \mathrm{H}, \mathrm{ddd}, \mathrm{J}=$ $7.9,1.5,0.5 \mathrm{~Hz}$ ). $\lambda_{\max }$ (methanol $419 \mathrm{~nm}$ ).

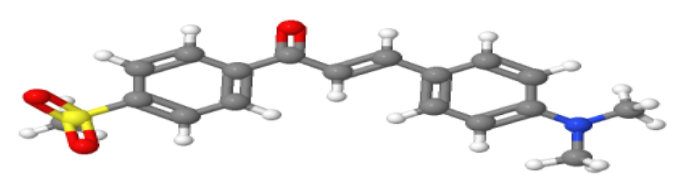

Figure 1 The molecular structure of MSPPP chalcone

\subsection{ZnO nanoparticle synthesis and doping mechanism}

A certain amount of zinc acetate dihydrate was dissolved in $75 \mathrm{~mL}$ of methanol, after stirring for 50 min. Further, an amount of double distilled water solution $(50 \mathrm{~mL})$ of tartaric acid was added dropwise to the previous mixture. The gel formed rapidly [10 minutes] at room temperature under vigorous magnetic stirring and dried at $100^{\circ} \mathrm{C}$ for $12 \mathrm{~h}$. Subsequently, the dry gel was first grinded and annealed at $550^{\circ} \mathrm{C}$ for $1 \mathrm{~h}$. A 0.5 and $1.5 \%$ of MSPPP chalcone were added to the prepared $\mathrm{ZnO}$ nanoparticle and milled for $5 \mathrm{~h}$ and annealed at $110^{\circ} \mathrm{C}$ for $1 \mathrm{~h}$.

\subsection{Material characterization}

The morphology of the materials samples was examined using a scanning electron microscope (SEM). The X-ray diffraction (XRD) was performed on a Bruker D8-Advance using $\mathrm{Cu} \mathrm{Ka}(\lambda=0.1541 \mathrm{~nm})$. The accelerating voltage and scanning angles were $40 \mathrm{kV}$ and $20^{\circ}-75^{\circ}$, respectively. The chemical bonding of the synthesized materials was investigated by means of Fourier transform infrared spectroscopy (FTIR): Model: Nicolet 6700 in the range $4000-400 \mathrm{~cm}^{-1}$ with a resolution of $4 \mathrm{~cm}^{-1}$. The diffusion reflection spectra (DRS) of the specimens synthesized were obtained in the range from 200 to $800 \mathrm{~nm}$ by using JASCO V-770 spectrophotometer: scans were performed at speed of $37 \mathrm{~nm} \mathrm{~min}{ }^{-1}$ with a bandwidth of $1 \mathrm{~nm}$.

\section{Result and Discussion}

3.1 characterization of pure $\mathrm{ZnO}, 0.5$ and $1.5 \%$ chalcone doped ZnO

\subsubsection{XRD analysis}

Figure 2 displayed the structure of pure and chalcone doped $\mathrm{ZnO}$ nanoparticles using X-ray diffraction patterns. The peak positions of pure $\mathrm{ZnO}$ were found at $2 \theta$ of $31.55^{\circ}, 34.32^{\circ}, 36.19^{\circ}$ $, 47.33^{\circ}, 56.43^{\circ}, 62.77^{\circ}$ and $67.91^{\circ}$. These peaks correspond to the (100), (002), (101), (102), (110), (103) and (112) planes of hexagonal wurtzite structure of $\mathrm{ZnO}$, respectively [18].

Table 1 XRD parameters data of $\mathrm{ZnO}$ and MSPPP chalcone doped $\mathrm{ZnO}$

\begin{tabular}{|c|c|c|c|c|c|c|}
\hline \multirow[t]{2}{*}{ Sample } & \multirow[t]{2}{*}{ Orientation } & \multirow[t]{2}{*}{$2 \theta$} & \multirow[t]{2}{*}{ Crystal size (nm) } & \multicolumn{2}{|c|}{ Lattice parameters } & \multirow[t]{2}{*}{$\mathrm{c} / \mathrm{a}$} \\
\hline & & & & $\mathrm{a}_{100}$ & $\mathrm{c}_{100}$ & \\
\hline \multirow{3}{*}{$\mathrm{ZnO}$} & $(100)$ & 31.62 & 25.73 & \multirow[t]{3}{*}{3.2646} & \multirow[t]{3}{*}{5.2287} & \multirow[t]{3}{*}{1.600} \\
\hline & $(002)$ & 34.27 & 23.48 & & & \\
\hline & $(101)$ & 36.12 & 27.46 & & & \\
\hline \multirow{3}{*}{$0.5 \%$ MSPPP chalcone - ZnO } & $(100)$ & 31.66 & 33.40 & \multirow[t]{3}{*}{3.2605} & \multirow[t]{3}{*}{5.2231} & \multirow[t]{3}{*}{1.602} \\
\hline & $(002)$ & 34.31 & 33.55 & & & \\
\hline & $(101)$ & 36.15 & 33.80 & & & \\
\hline \multirow[t]{3}{*}{$1.5 \%$ MSPPP chalcone - ZnO } & $(100)$ & 31.71 & 36.16 & \multirow[t]{3}{*}{3.2566} & \multirow[t]{3}{*}{5.2158} & \multirow[t]{3}{*}{1.602} \\
\hline & $(002)$ & 34.36 & 33.83 & & & \\
\hline & $(101)$ & 36.19 & 35.66 & & & \\
\hline
\end{tabular}




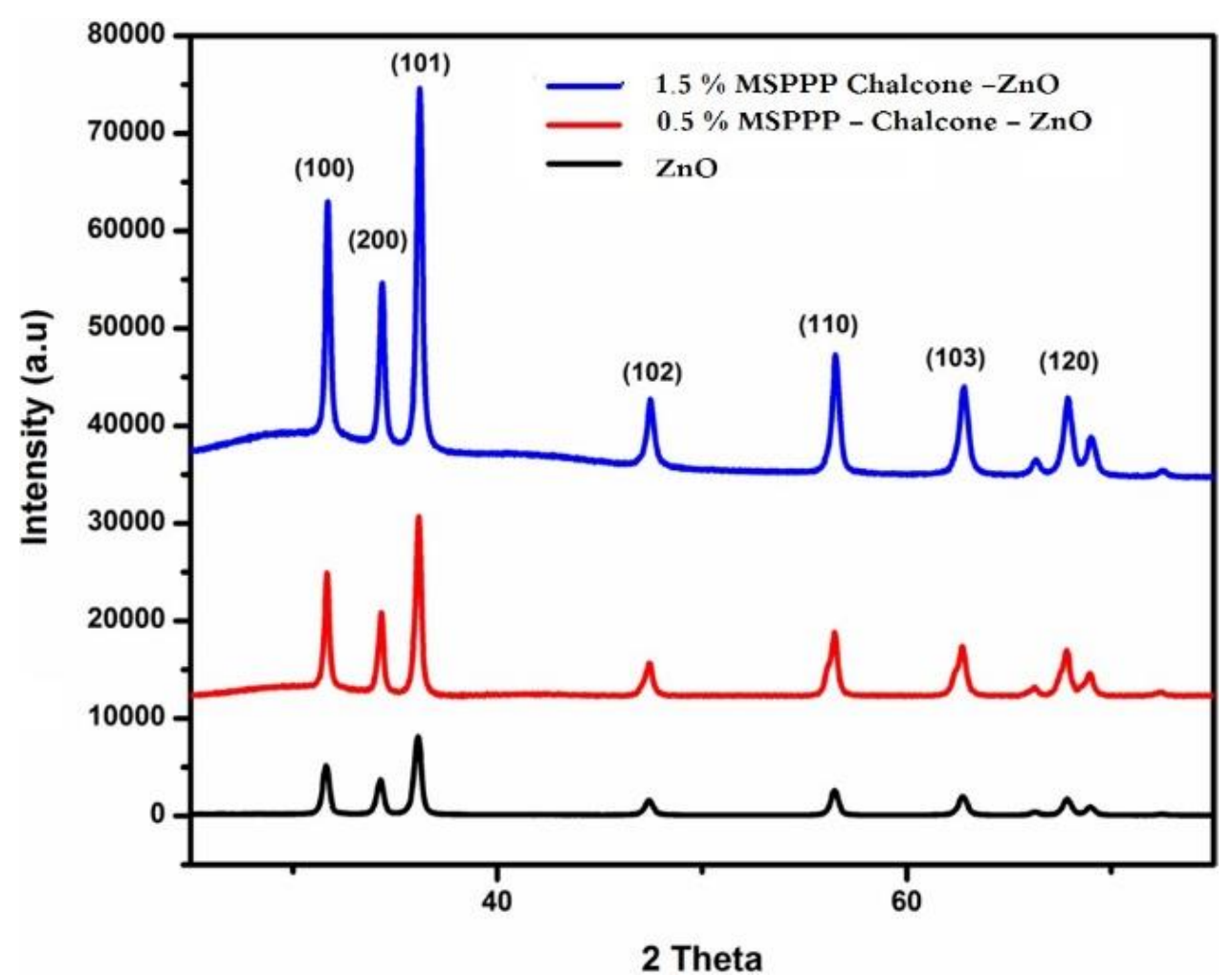

Figure 2 XRD pattern for undoped and MSPPP chalcone doped $\mathrm{ZnO}$

The doped samples showed peaks similar to $\mathrm{ZnO}$ nanoparticle patterns and no new peak has been detected in the XRD patterns. The average crystallite size (D) was calculated using Scherrer's [19].

$$
\mathrm{D}=\frac{0.9 \lambda}{\beta \cos \theta}
$$

where $\lambda$ the wavelength of $\mathrm{Cu}$ Ka radiation, $\beta$ is the full a width half maximum (FWHM) of the diffraction peak and is the Bragg peak angle. Table 1 displayed the average crystallite size (D). The crystallite size of pure $\mathrm{ZnO}$ varied from 23.48 to $27.46 \mathrm{~nm}$. Increasing the chalcone percentage by 0.5 and $1.5 \%$ has increased the crystallite sizes in the range of $33.40-33.80 \mathrm{~nm}$ and $33.83-36.16 \mathrm{~nm}$, respectively.

The lattice parameters $\mathrm{a}$ and $\mathrm{c}$ can be calculated by using Eqs. (2) and (3) [20]:

$$
\begin{aligned}
& \mathrm{a}=\frac{\lambda}{\sqrt{3} \sin \theta} \\
& \mathrm{c}=\frac{\lambda}{\sin \theta}
\end{aligned}
$$

\subsubsection{SEM of materials}

Undoped, 0.5 and 1.5\% MSPPP chalcone doped ZnO nanoparticles SEM images are shown in Fig. $3(a-c)$. The high magnification SEM images show that the entangled $\mathrm{ZnO}$ nanoparticles appear in the form of a clear hexagonal structure. The morphology of the chalcone doped $\mathrm{ZnO}$ samples changed and the surface area decreased with increasing the particle size. This decrease in the surface area can be attributed to the molecular structural disorder and lattice strains attributed to chalcone dopant. However, the dopant samples showed more surface porosity compared with $\mathrm{ZnO}$.

\subsubsection{FTIR of $\mathrm{ZnO}$ and MSPPP chalcone doped - Zno}

FTIR was used to measure the vibration and bending modes of the structure of $\mathrm{ZnO}, 0.5$ and $1.5 \%$ doped-ZnO at room temperature. The spectra are shown in Fig. 4. The broad absorption band at 3439.39, $1077.74 \mathrm{~cm}^{-1}$, can be attributed to the normal polymeric $\mathrm{O}-\mathrm{H}$ stretching vibration of $\mathrm{H}_{2} \mathrm{O}$, in ZnO lattices [21]. Other sharp peaks observed at 1621.45 and $1615.60 \mathrm{~cm}^{-1}$ can be attributed to $\mathrm{H}-\mathrm{O}-\mathrm{H}$ bending vibration, which in turn can be assigned to the small amount of $\mathrm{H}_{2} \mathrm{O}$ in the $\mathrm{ZnO}$ nanocrystal, also, the absorption band observed between 2300 and $2400 \mathrm{~cm}^{-}$ ${ }^{1}$ are due to the existence of $\mathrm{CO}_{2}$ molecule in the air. The vibration band at446.31 $\mathrm{cm}^{-1}$ assigned to the stretching mode of pure $\mathrm{ZnO}$ [21] while the band shifted to 445.51 and $450.18 \mathrm{~cm}^{-1}$ for the dopant 0.5 and $1.5 \%$, respectively. This shift might be attributed to the formation of a new bond between the chalcone and $\mathrm{ZnO}$ (Table 2). 

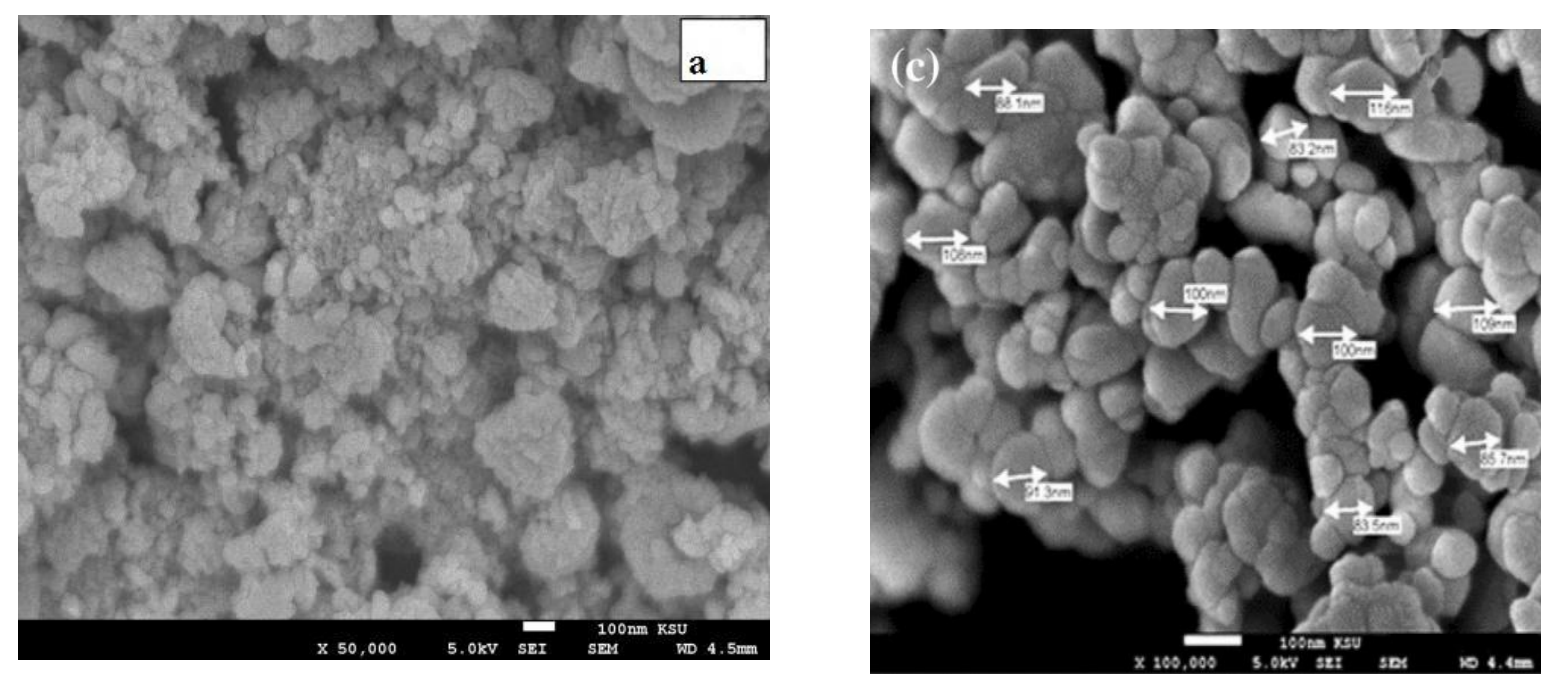

Figure $3(\mathrm{a}-\mathrm{c})$ SEM images of undoped, 0.5 and $1.5 \%$ MSPPP chalcone doped $\mathrm{ZnO}$ nanoparticles.
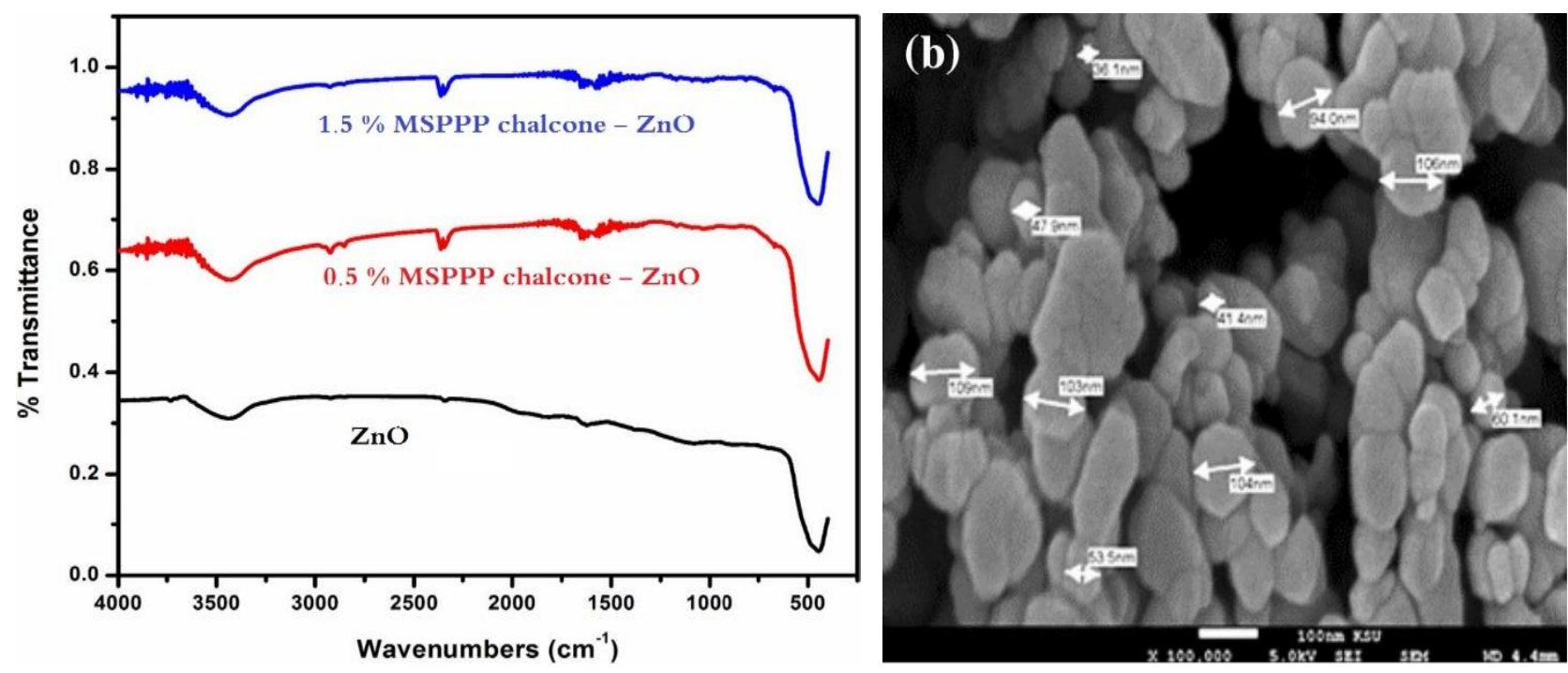

Figure 4 FTIR spectra of $\mathrm{ZnO}$ and MSPPP chalcone doped $\mathrm{ZnO}$

\subsubsection{Optical Properties}

The optical absorption spectra are shown in Fig. 5 with wavelength range $300 \mathrm{~nm}-1100 \mathrm{~nm}$. When the $\mathrm{ZnO}$ was doped with the chalcone by a ratio of $0.5 \%$, the absorption edge $(395 \mathrm{~nm})$ red shifted to $415 \mathrm{~nm}$. When the dopant was increased to $1.5 \%$, the absorption edge of the spectrum remained unchanged. The band gaps of the fabricated nanoparticles were calculated using Tauc Eq. [22].

$$
\alpha \mathrm{h} v=\mathrm{B}\left(\mathrm{h} v-\mathrm{E}_{\mathrm{g}}\right)^{\mathrm{n}}
$$

where $a$ is absorption coefficient, Eg represent optical band gap, B is band tailing parameter, hv is the photon energy, and $\mathrm{n}=0.5$ for direct band gap. The energy band gap is determined by extrapolating the straight portion of the curve between (ahv) 2 and hv when a equal to zero. The value of the energy gap (Eg) for $\mathrm{ZnO}$ nanoparticles was $3.14 \mathrm{eV}$. This value is in a good agreement with some previous studies [4, 23]. For 0.5 and $1.5 \%$ chalcone doped $\mathrm{ZnO}$, the energy gap decreased by an order of magnitude $0.16 \mathrm{eV}$ as seen in Fig. 6. However, the introduction of chalcone on $\mathrm{ZnO}$ increased the optical density of the absorption spectrum in the visible region. The good absorption in the UV and visible regions for the chalcone doped $\mathrm{ZnO}$ can open a new window for solar cell applications. 
Table 2 FTIR for all specimens

\begin{tabular}{|l|l|l|l|}
\hline \multirow{2}{*}{ Assignment } & \multicolumn{2}{|l|}{ Wavenumber $\left(\mathrm{cm}^{-1}\right)$} \\
\cline { 2 - 4 } & Pure $\mathrm{ZnO}$ & $0.5 \%$ MSPPP chalcone $-\mathrm{ZnO}$ & $1.5 \%$ MSPPP chalcone - ZnO \\
\hline $\mathrm{O}-\mathrm{H}$ stretching modes & 3443.34 & 3435.01 & 3435.25 \\
\hline $\mathrm{CO}_{2}$ stretching modes & 2343.19 & 2351.45 & 2357.68 \\
\hline $\mathrm{Zn}-\mathrm{O}$ stretching vibration & 445.98 & 447.55 & 453.21 \\
\hline $\mathrm{H}-\mathrm{O}-\mathrm{H}$ bending vibration & 1077.67 & 1031.26 & 1023.12 \\
\hline
\end{tabular}

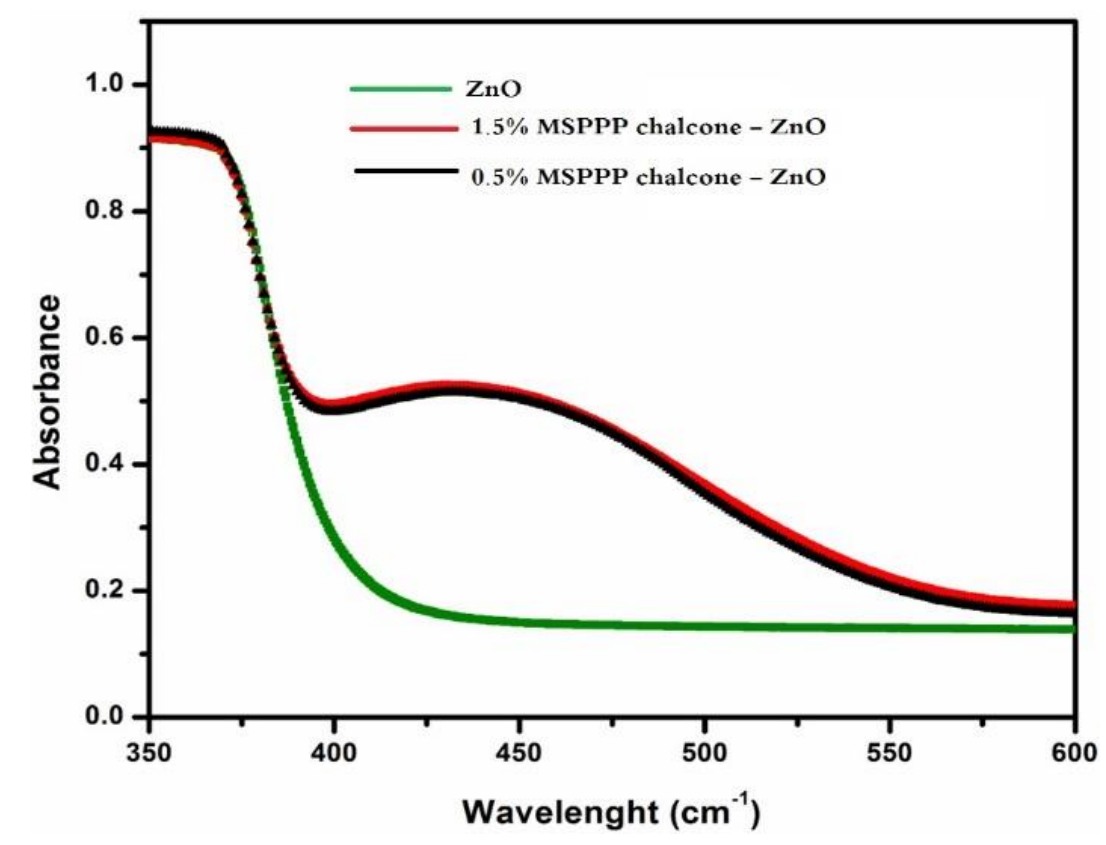

Figure 5 UV - Vis diffuse reflection spectra of ZnO and MSPPP chalcone doped ZnO

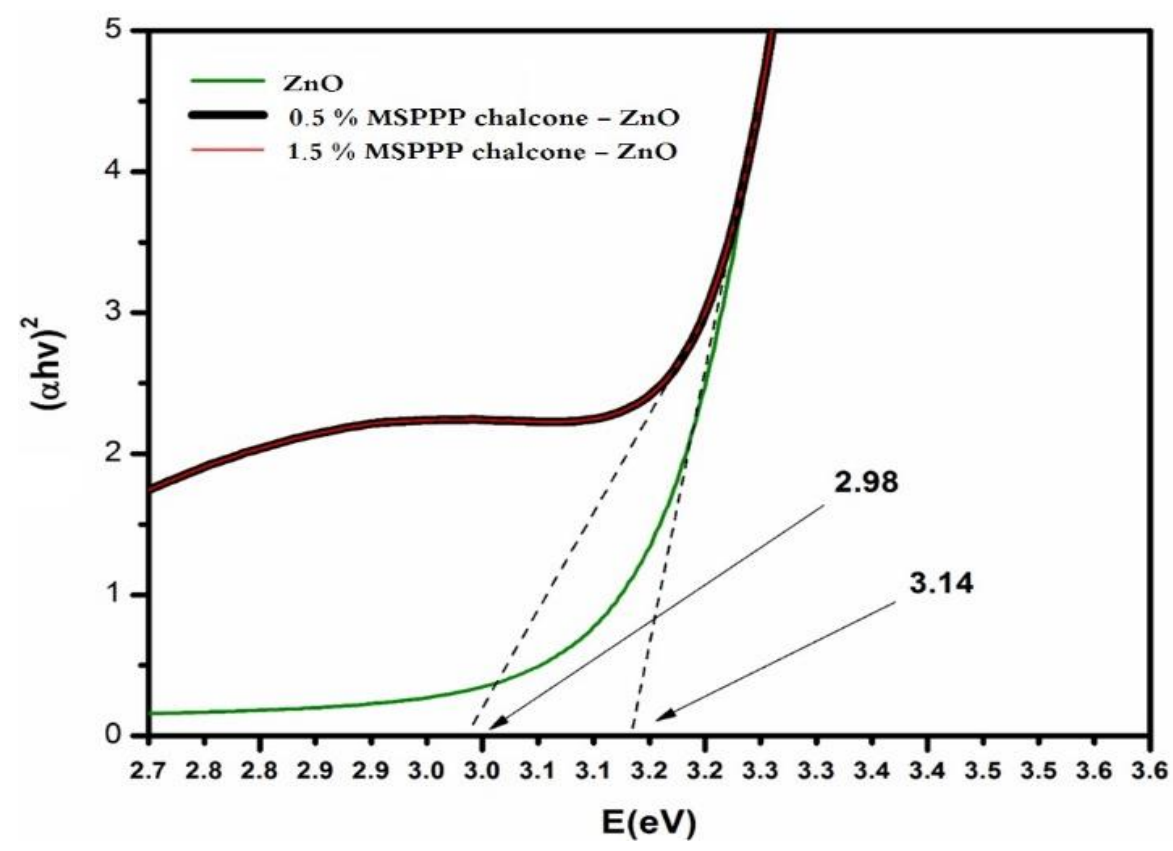

Figure $6(\mathrm{ahv})^{2}$ against photon energy (eV) in $\mathrm{ZnO}$ and chalcone doped $\mathrm{ZnO}$ 


\section{Conclusion}

A chalcone derivative, of 1-(4-Methylsulfonyl Phenyl)-3-(4-n, n Dimethyl (amino Phenyl)-2-Propen1-One (MSPPP) was prepared and added to pure $\mathrm{ZnO}$ nanoparticles with 0.5 and 1.5 wt\% doping percentages. It was found that the value of the energy gap (Eg) for $\mathrm{ZnO}$ nanoparticles was $3.14 \mathrm{eV}$ and for 0.5 and $1.5 \%$ chalcone doped $\mathrm{ZnO}$, the energy gap decreased by an order of magnitude $0.16 \mathrm{eV}$. Also, it was found that the increasing dopant percentage distorted the hexagonal shape of $\mathrm{ZnO}$ nanoparticles. Further, the lattice parameters and microstrain were decreased while the crystallite size was increased. Chalcone loading on $\mathrm{ZnO}$ has decreased the energy bandgap.

\section{References}

[1] S. Singhal, J. Kaur, T. Namgyal, R. Sharma, Cu-doped ZnO nanoparticles: synthesis, structural and electrical properties. Physica B: Condensed Matter, 407 (2012) 1223-1226. [DOI]

[2] J. Pei, D. Jiang, M. Zhao, Q. Duan, R. Liu, L. Sun, Z. Guo, J. Hou, J. Qin, B. Li, G. Zhang, Controlled enhancement range of the responsivity in $\mathrm{ZnO}$ ultraviolet photodetectors by Pt nanoparticles, Applied Surface Science, 389 (2016) 1056-1061. [DOI]

[3] F. Meng, J. Yin, Y.Q. Duan, Z.H. Yuana, L.J. Bie, Co-precipitation synthesis and gas-sensing properties of $\mathrm{ZnO}$ hollow sphere with porous shell, Sensors and Actuators B: Chemical, 156 (2011) 703-708. [DOI]

[4] M.F. Attia, Effect of Annealing and Thickness on Some Physical Characteristics of ZnO Films, Journal of Materials Science Research and Reviews, 2 (2019) 1-8.

[5] N. Vasilyev, B. V. Novikov, I. Kh. Akopyan, M. E. Labzovskaya, ZnO-based random lasing on nanoparticles realized by laser induced breakdown, Journal of Luminescence, 182 (2017) 45-48. [DOI]

[6] M. F. Attia, Study on Electrical, Optical Properties of $\mathrm{ZnSe} / \mathrm{SiO}_{2}$ Composite Thin Film Using Sol-Gel Dip Coating Techniques, Journal of Materials Science Research and Reviews, 3 (2019) 1-13.
[7] Z. Liu, C. Cheng Liu, J. Ya, E. Lei, Controlled synthesis of $\mathrm{ZnO}$ and $\mathrm{TiO}_{2}$ nanotubes by chemical method and their application in dyesensitized solar cells, Renewable Energy, 36 (2011) 1177-1181. [DOI]

[8] K. Hembram, D. Sivaprahasam, T.N. Rao, Combustion synthesis of doped nanocrystalline $\mathrm{ZnO}$ powders for varistors applications, Journal of the European Ceramic Society, 31 (2011) 1905-1913. [DOI] [PubMed]

[9] H. Kuang, P. Yang, L. Yang, Z.P. Aguilar, H. $\mathrm{Xu}$, Size dependent effect of $\mathrm{ZnO}$ nanoparticles on endoplasmic reticulum stress signaling pathway in murine liver, Journal of Hazardous Materials, 317 (2016) 119-126. [DOI] [PubMed]

[10] S.V. Bhat, F. Deepak, Tuning the bandgap of $\mathrm{ZnO}$ by substitution with $\mathrm{Mn}^{2+}, \mathrm{Co}^{2+}$ and $\mathrm{Ni}$ ${ }^{2+}$, Solid State Communications, 135 (2005) 345-347. [DOI]

[11] S. Deka, P.A. Joy, Synthesis and magnetic properties of $\mathrm{Mn}$ doped $\mathrm{ZnO}$ nanowires, Solid State Communications, 142 (2007) 190-194. [DOI]

[12] X. Zhang, Y. Chen, S. Zhang, C. Qiu, High photocatalytic performance of high concentration Al-doped $\mathrm{ZnO}$ nanoparticles, Separation and Purification Technology, 172 (2017) 236-241. [DOI]

[13] M. Go, X. Wu, X. Liu, Chalcones: an update on cytotoxic and chemoprotective properties, Current Medicinal Chemistry, 12 (2005) 483499. [DOI] [PubMed]

[14] M.F. Attia, Synthesis, Properties of a New (Polymer and Chalcone), Asian Journal of Physical and Chemical Sciences, 7 (2019) 1-9. [DOI]

[15] L. Yu, W. Chen, D. Li, J. Wang, Y. Shao, M. He, $P$. Wang, $X$. Zheng, Inhibition of photocorrosion and photoactivity enhancement for $\mathrm{ZnO}$ via specific hollow $\mathrm{ZnO}$ core/ZnS shell structure, Applied Catalysis B: Environmental, 164 (2015) 453-461. [DOI]

[16] M.F. Attia, Effect of Different Annealing Temperatures on Structural, Optical, Morphological and Electrical Properties of $\mathrm{Cu}$ ZnO Thin Films Prepared Using Sol-gel Spin 
Coating Techniques, Journal of Materials Science Research and Reviews, 3 (2019) 1-25.

[17] M.F. Attia, A.A. Elbadawi, K.H. Ibnaouf, A.O. Elzupir, Influence of Functional Groups on the Photophysical Properties of 1-(4-Methylsulfonyl Phenyl)-3-(4-n, n Dimethyl (amino Phenyl)-2Propen-1-One Chalcone as Laser Dye, Asian Journal of Physical and Chemical Sciences, 9 (2021) 22-29. [DOI]

[18] A. Modwi, M.K.M. Ali, Kamal K. Taha, M.A. Ibrahem, H.M.El-Khair, M.H. Eisa, M.R. Elamin, O. Aldaghri, Raed Alhathlool, K.H. Ibnaouf, Structural and optical characteristic of chalcone doped $\mathrm{ZnO}$ nanoparticles, Journal of Materials Science: Materials in Electronics, 29 (2018) 2791-2796. [DOI]

[19] M. Caglar, F. Yakuphanoglu, Structural and optical properties of copper doped $\mathrm{ZnO}$ films derived by sol-gel, Applied Surface Science, 258 (2012) 3039- 3044. [DOI]

[20] M. Ali, K. Ibrahim, E. Mkawi, Ag-Al alloy thin film on plastic substrate by screen printing for solar cell back contact application, Materials Science in Semiconductor Processing, 16 593597 (2013). [DOI]

[21] M.F. Attia, Effect of Different Annealing Temperatures on Structural, Optical, Morphological and Electrical Properties of $\mathrm{Cu}$ ZnO Thin Films Prepared Using Sol-gel Spin Coating Techniques, Journal of Materials Science Research and Reviews, 3 (2019) 1-25.

[22] R. Chauhan, A. Kumar, R.P. Chaudhary, Structure and optical properties of $\mathrm{Zn}_{1-x} \mathrm{Nix} O$ nanoparticles by coprecipitation method, Journal of Optoelectronics and Biomedical Materials, 3 (2011) 17-23. [DOI]

[23] M.F. Attia, Copper Doped Zinc Oxide Nanocrystalline Thin Film: Growth, Characterization, Effect of annealing on Photocatalytic activity and electrical properties of irradiated film, Applied Physics, 2018.

\section{Authors' contribution}

This work was carried out in collaboration among all authors. Authors Mohana Attia, Abdelrahman A. Elbadawi conceived of the presented idea. Author MFA developed the theory and performed the computations and verified the analytical methods. All authors discussed the results and contributed to the final manuscript.

\section{Competing Interests}

The authors declare that there are no personal, organizational or financial conflicts of interest.

\section{Funding}

No funding was received for conducting this study.

\section{Does this article screened for similarity? Yes}

\section{Conflict of interest}

The authors have no conflicts of interest to declare that they are relevant to the content of this article.

\section{About the License}

(C) The author(s) 2021. The text of this article is open access and licensed under a Creative Commons Attribution 4.0 International License 